Weissman (Ed.), Methods of RNA and DNA Sequencing. Praeger Press, New York.

14.Sosnowski, R.G., E. Tu, W.F. Butler, J.P. O'Connell and M.J. Heller. 1997. Rapid determination of single base mismatch mutations in DNA hybrids by direct electric field control. Proc. Natl. Acad. Sci. USA94:11191123.

15.Swerdlow, H., B.J. Jones and C.T. Wittwer. 1997. Fully automated DNA reaction and analysis in a fluidic capillary instrument. Anal. Chem. 69:848-855.

16. Weast, R.C. and M.J. Astle. 1983. The viscosity of water, p. F-40. CRC Handbook of Chemistry and Physics. CRC Press, Boca Raton, FL.

17.Thomas, S.M., R.F. Moreno and L.L. Tilzer. 1989. DNA extraction with organic solvents in gel barrier tubes. Nucleic Acids Res. 17:5411.

18. Wittwer, C.T., G.C. Fillmore and D.J. Garling. 1990. Minimizing the time required for DNA amplification by efficient heat transfer to small samples. Anal. Biochem. 186:328331.

19. Wittwer, C.T. and D.J. Garling. 1991. Rapid cycle DNA amplification: time and temperature optimization. BioTechniques 10:76-83.

20.Wittwer, C.T. and M.G. Herrmann. 1999. Rapid thermal cycling and PCR kinetics, p. 211-230. In M.A. Innis, D.H. Gelfand and J.J. Sninsky (Eds.), PCR Applications: Protocols for Functional Genomics. Academic Press, San Diego, CA

21.Wittwer, C.T., B.C. Marshall, G.H. Reed and J.L. Cherry. 1993. Rapid cycle allelespecific amplification: studies with the cystic fibrosis delta F508 locus. Clin. Chem. 139:804-809.

22.Wittwer, C.T., G.B. Reed and K.M. Rire. 1994. Rapid cycle DNA amplification, p. 174181. In K.B. Mullis, F. Ferre and R.A. Gibbs (Eds.), The Polymerase Chain Reaction. Birkhauser, Boston, MA.

23. Wetmur, J.G. and N. Davidson. 1968. Kinetics of renaturation of DNA. J. Mol. Biol. $31: 349-370$.

This work was supported by a Biomedical Engineering Research grant to C.T.W. from the Whittaker Foundation. Address correspondence to Dr. Carl T. Wittwer. Department of Pathology, University of Utah, $50 \mathrm{~N}$. Medical Dr., Salt Lake City, UT 84132, USA. e-mail:carl_wittwer@hlthsci.med.utah.edu

Received 7 April 2000; accepted 11 July 2000 .

\author{
David M. Heap, \\ Mark G. Herrmann and \\ Carl T. Wittwer \\ University of Utah \\ Salt Lake City, UT, USA
}

\section{Nuclear Run-On Assay Using Biotin Labeling, Magnetic Bead Capture and Analysis by Fluores- cence-Based RT-PCR}

BioTechniques 29:1012-1017 (November 2000)

\section{ABSTRACT}

In this report, we present a fluorescencebased approach to the assessment of cellular gene expression and transcription rates. Nuclear run-on was performed by supplying biotin-16-UTP to nuclei, and labeled transcripts were bound to streptavidin-coated magnetic beads. Total cDNA was then synthesized by means of random hexamer primed reverse transcription of captured molecules. To monitor transcript abundance in cDNA, both from nuclear run-on and total RNA, we propose a semiquantitative PCR approach based on the use of fluorescent primers.

\section{INTRODUCTION}

Quantitative analysis of mRNA species in different experimental conditions is crucial to the study of gene expression. The total amount of any mRNA is principally determined by the rate of new gene transcription and the stability of the mRNA. Therefore, besides analyzing total RNA levels of a specific gene, it is often useful to assess the rate of its nuclear transcription through the nuclear run-on assay $(5,12)$. In the classical run-on technique, isolated nuclei are incubated with $[\alpha-$ 32P]UTP to label both nascent transcripts and elongated RNA molecules. Newly synthesized RNA is then used to detect specific transcripts by filter hybridization. This procedure guarantees sensitivity and accuracy. Nonetheless, it is often time consuming and requires the hazardous handling of a considerably high specific activity of $\alpha-32 \mathrm{P}$.

A modified nonradioactive technique using digoxigenin-labeled UTP and chemiluminescent detection was described (7). In this case, the impossibility of monitoring the filter washing conditions and the narrow range of exposure times dramatically reduce the protocol flexibility.

As an alternative to filter hybridization, a novel method was reported (9) in which the run-on reaction was performed either with or without nucleotides, and the overall transcript amount was detected by RT-PCR; the difference between PCR yields from samples incubated with and without nucleotides was taken as a measure of transcription rates. Considering the huge excess of RNA in nuclei before the reaction and the high variability among different nuclei aliquots, this approach might lead to inaccurate quantification.

Hence, we sought to develop a straightforward and safe approach to the assessment of cellular gene expression and transcription rates, which is presented in this report. For the synthesis of nuclear RNA, biotin-16-UTP was supplied to nuclei, and labeled RNA was captured by streptavidin-coated magnetic beads. RNA-binding beads were then used for random hexamer primed reverse transcription. A semiquantitative fluorescent PCR approach was applied to monitor transcript abundance in cDNA derived from both nuclear run-on and total RNA.

To set up proper conditions for the proposed techniques, we performed retinoic acid (RA) and cycloheximide treatments in neuroblastoma SK-N-BE cells and characterized the activation of the $R E T$ proto-oncogene $(2,3)$ expression and transcription upon such treatments.

\section{MATERIALS AND METHODS}

\section{Cell Lines and Growth Conditions}

Human neuroblastoma IMR-32 and SK-N-BE cells, a gift of Prof. Della Valle (University of Bologna, Italy), were grown in RPMI medium (Hyclone Laboratories, Logan, UT, USA), supplemented with $10 \%$ fetal calf serum (FCS) (Life Technologies Italia Srl, Milano, Italy), $2 \mathrm{mM}$ L-glutamine, $100 \mathrm{U} / \mathrm{mL}$ penicillin and $100 \mu \mathrm{g} / \mathrm{mL}$ streptomycin. Where indicated, a 4-h treatment with 1 $\mu \mathrm{M}$ RA and $20 \mathrm{mg} / \mathrm{mL}$ cycloheximide was performed (1,8). All-trans-RA (Sigma-Aldrich Srl, Milano, Italy) was dissolved in ethanol and added to the 
cell medium containing $10 \%$ charcoaltreated FCS. Cycloheximide (Roche Molecular Biochemicals, Monza, Milano, Italy) was dissolved in water. In control samples, ethanol alone $(0.1 \%$ final concentration) was added to medium containing $10 \%$ charcoal-treated FCS.

\section{Nuclei Preparation}

Nuclei were prepared with minor modifications to standard protocols (11): $30-80 \times 10^{6}$ cells were collected by trypsination, centrifuged $\left(4^{\circ} \mathrm{C}, 270 \times\right.$ $g$ ) and washed twice with PBS devoid of calcium and magnesium. The pellet was resuspended in $4 \mathrm{~mL}$ cell lysis buffer [10 mM Tris-HCl, pH 7.4, 3 mM $\mathrm{MgCl}_{2}, 10 \mathrm{mM} \mathrm{NaCl}, 150 \mathrm{mM}$ sucrose and $0.5 \%$ Nonidet ${ }^{\circledR}$ P-40 (NP40)], and a 5-min incubation in ice followed. Nuclei were then collected by centrifugation $\left(4^{\circ} \mathrm{C}, 170 \times g\right)$ and gently washed with cell lysis buffer devoid of NP40. After centrifugation, the pellet was resuspended in $100 \mu \mathrm{L}$ freezing buffer (50 mM Tris- $\mathrm{HCl}, \mathrm{pH} 8.3,40 \%$ glycerol, $5 \mathrm{mM} \mathrm{MgCl}_{2}$ and $0.1 \mathrm{mM}$ EDTA).

\section{In Vitro RNA Synthesis and Purification}

One volume of transcription buffer $2 \times[200 \mathrm{mM} \mathrm{KCl}, 20 \mathrm{mM}$ Tris- $\mathrm{HCl}, \mathrm{pH}$ 8.0, $5 \mathrm{mM} \mathrm{MgCl}_{2}, 4 \mathrm{mM}$ dithiothreitol (DTT), $4 \mathrm{mM}$ each of ATP, GTP and CTP, $200 \mathrm{mM}$ sucrose and $20 \%$ glycerol] was gently added to nuclei in ice, $8 \mu \mathrm{L}$ biotin-16-UTP (from $10 \mathrm{mM}$ tetralithium salt; Roche Molecular Biochemicals) was supplied to the mixture, which was incubated for $30 \mathrm{~min}$ at $29^{\circ} \mathrm{C}$. Reaction was stopped by adding $6 \mu \mathrm{L} 250 \mathrm{mM} \mathrm{CaCl} 2,6 \mu \mathrm{L}$ RNase-free DNase I (10 U/ $\mu \mathrm{L}$; Roche Molecular Biochemicals) and incubating for 10 min at $29^{\circ} \mathrm{C}$. RNA purification of both nuclear run-on and total RNA was performed with TRIzOL ${ }^{\circledR}$ reagent (Life Technologies) according to the manufacturer's instructions. RNA was resuspended in $50 \mu \mathrm{L}$ diethylpyrocarbonate (DEPC)-treated water.

\section{RNA Binding to Magnetic Beads}

Dynabeads M-280 (50 $\mu \mathrm{L}$; Dynal, A.S., Oslo, Norway) (10) resuspended in binding buffer (10 mM Tris- $\mathrm{HCl}, \mathrm{pH}$
7.5, $1 \mathrm{mM}$ EDTA and $2 \mathrm{M} \mathrm{NaCl}$ ) were mixed to an equal volume of run-on RNA and incubated $20 \mathrm{~min}$ at $42^{\circ} \mathrm{C}$ and $2 \mathrm{~h}$ at room temperature. Beads were separated by the magnetic apparatus supplied by Dynal, and a 15-min washing in $500 \mu \mathrm{L} 15 \%$ formamide and $2 \times$ standard saline citrate (SSC) was performed twice, followed by a 5-min washing in $1 \mathrm{~mL} 2 \times \mathrm{SSC}$. Beads were then resuspended in $30 \mu \mathrm{L} \mathrm{DEPC}$-treated water and stored at $-20^{\circ} \mathrm{C}$.

\section{Semiquantitative RT-PCR}

Random hexamer primed cDNA was prepared from 3-10 $\mu \mathrm{L}$ run-on RNA or $500 \mathrm{ng}$ total RNA. A set of 8-16 progressive 1:2 dilutions of cDNA was prepared. Three microliters of each sample were used in $30-\mu \mathrm{L}$ reactions with 6 -fluoro amidite (6-fam) fluorescent forward primers. The human housekeeping G3PDH gene sequence was amplified with the forward primer, 5'-TGAAG GTCGGAGTCAACGGATTTGGT-3', and the reverse primer, 5'-GCAG AGATGATGACCCTTTTGGCTC-3', to give a 358 -bp product (25 cycles). The human RET gene sequence was am plified with the forward IP18F primer, 5'-GGATTTCGGCTTGTCCCGAG-3', and the reverse IP20R primer, $5^{\prime}-\mathrm{CC}$ ATGTGGAAGGGAGGGCTC- $3^{\prime}$, to give a 491-bp product (38 cycles) (2). One-tenth of each amplified sample was analyzed by polyacrylamide denaturing gel electrophoresis on a Model 373 DNA sequencer (Applied Biosystems, Foster City, CA, USA). Product abundance was assessed through the area underneath the fluorescent peak, by means of the GeneScan ${ }^{\circledR} 672$ software (Applied Biosystems).

\section{Statistical Analysis}

Lines correlating PCR yield to cDNA concentration were determined by the IGOR Pro software (WaveMetrics, Lake Oswego, OR, USA), and relative transcript abundance was evaluated through the ratio between the RET and the G3PDHline slopes (R value). In RA and cycloheximide treatments, different $\mathrm{R}$ values were determined both from independent treatments and, for each treatment, from independent groups of reactions. Differences between $\mathrm{R}$ values derived from treated and untreated cells were determined by means of the Student's $t$-test available online (Tools for Science, Statistics Web site, at www. physics.csbs.ju.edu/stats).

\section{RESULTS}

\section{Setting Up Conditions for Proper Labeling and Purification of Run- On RNA}

Eukaryotic nuclei used in run-on assays already contain a great amount of RNA, and new transcripts derived from in vitro transcription indeed represent a minor proportion of such molecules. Taking this into account, we sought to perform the run-on assay in such a way that newly synthesized RNA could be later separated from unlabeled molecules. In this line, biotin-16-UTP was supplied to nuclei in a standard reaction, RNA extracted by means of TRIZOL purification and Dynabeads used to trap the biotinylated molecules. In our approach, biotin-16-UTP is incorporated along the RNA molecules at any position, identically to what happens with radioactive $[\alpha-32 \mathrm{P}] \mathrm{UTP}$, thus labeling both nascent molecules and elongated ones.

To monitor undesired RNA capture to Dynabeads, we set up control reactions in which UTP was added to the mixture in the place of biotin-16-UTP, and binding was performed. In this condition, if effective washing occurs, the following RT-PCR will give a blank product. Among the different washing conditions tested, the one reported in Materials and Methods allowed for thorough purification of run-on RNA.

\section{Determination of the Linear Range of Fluorescent RT-PCRs}

Our RT-PCR approach is based on the assumption that, within the exponential phase of a PCR, there is a linear correlation between template (cDNA) concentration and reaction product (4). Up to 16 serial 1:2 dilutions are prepared from cDNA, derived either from nuclear run-on or total RNA. Reactions are set up with a fluorescent forward primer at a fixed cycle number, and the products are run on a DNA sequencing 
apparatus. The amount of PCR product is calculated through the area underlying the fluorescent peak on the gel, peak areas plotted against cDNA concentrations and regression lines plotted. For any given cDNA and PCR, the range of sample dilutions allowing for linear correlation is to be determined. The GeneScan software gives a definite value of peak area only when the signal is above a certain threshold. Therefore, to avoid personal bias in determining the linear range, we decided to plot regression lines using the first point "visible" on the gel, the two following ones, plus the blank sample. Relative transcript abundance of any given gene can be evaluated through the ratio between its line slope and that of a housekeeping gene ( $R$ value). Figure 1 shows an example of curve fitting for the housekeeping G3PDHgene in cDNA derived from neuroblastoma IMR-32 cells.

\section{An Application of the Proposed Technique}

Experiments performed in different laboratories have shown that in neuroblastoma cells the RET proto-oncogene expression is enhanced by RA treatment $(1,8,13)$. Bunone et al. (1) analyzed both total RNA and run-on transcripts upon treatment of SK-N-BE

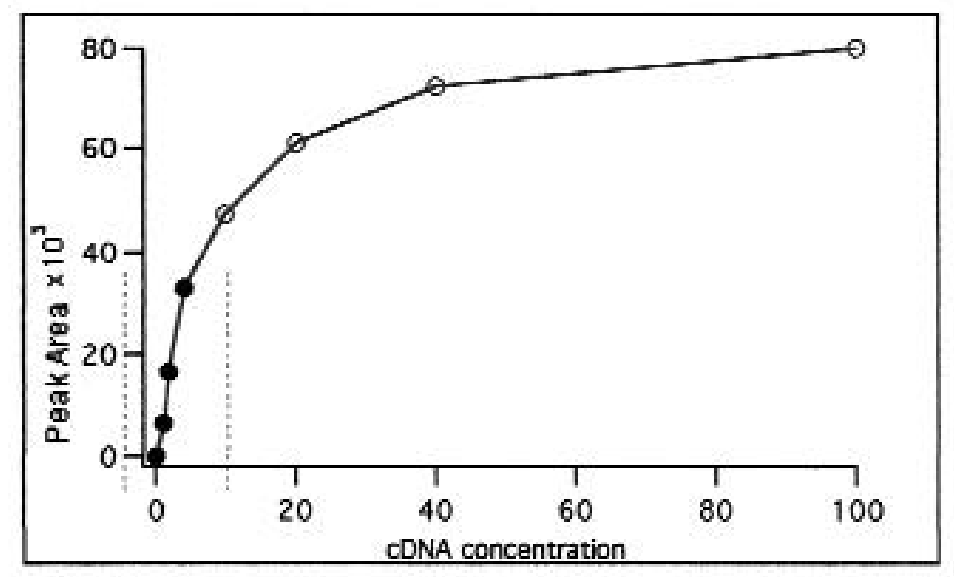

a) G3PDH from neuroblastoma IMR-32 total RNA

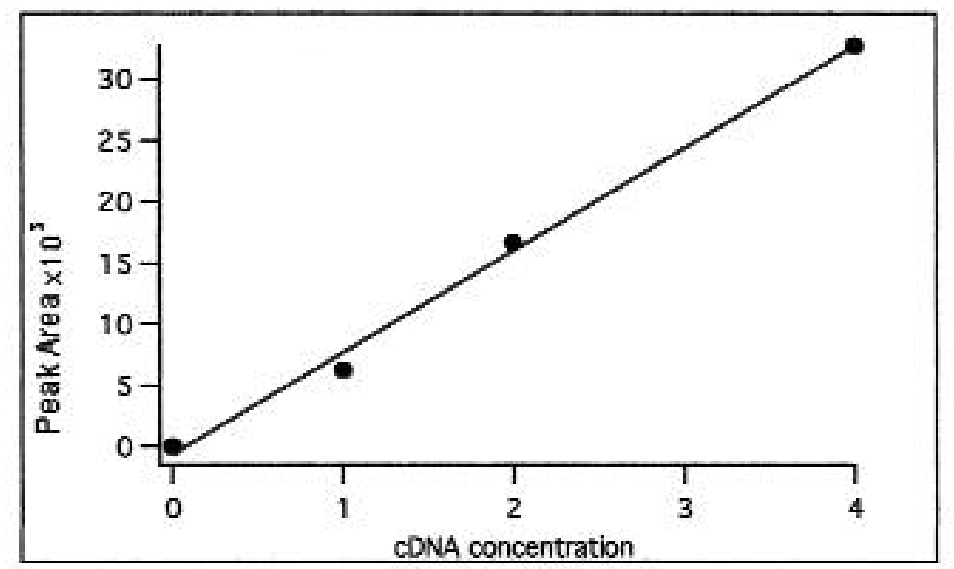

b) G3PDH from neuroblastoma IMR-32 total RNA

Figure 1. An example of curve fitting. The $G 3 P D H$ gene was amplified using cDNA from IMR-32 cells. (a) Depicts all points of amplification, the curve reaching a plateau with the most concentrated sam ples, while (b) represents the linear range used in regression analysis (filled circles). Peak area refers to the absolute value of fluorescent PCR product, while cDNA concentration is a relative value, 1 referring to the most diluted sample and 0 to the blank sample.

cells with RA and cycloheximide, thus collecting evidence that RA exerts its action by enhancing the level of the gene transcription.

To compare results collected by our techniques to those collected with standard procedures, we performed 4-h RA and cycloheximide treatments in neuroblastoma SK-N-BE cells. The RET gene RNA levels in treated and untreated cells were compared, using the G3PDHgene as an internal control of housekeeping gene expression. As shown in Figure 2, both total RNA expression and nuclear transcription are enhanced in treated cells, and the observed difference is statistically significant.

\section{DISCUSSION}

In this report, a novel approach to the run-on transcription assay is presented. Experiments performed with the described protocol led to the same results as compared to published data obtained with standard procedures. Statistical 
analysis on independent experiments was undertaken. Thus, reliability and reproducibility of the proposed technique were assessed. Our approach shows some intriguing advantages. First, it is safe and easily performed. Second, purified RNA can be used for different independent cDNA synthesis and stored for later use. The sensitivity of PCR allows detection of rare transcripts. Thus, by carefully adapting dilution conditions, comparisons can be made between cells or cellular states in which highly variable levels of a given transcript are to be detected. One major drawback of filter hybridization in standard run-on is nonspecific hybridization, especially when homologous genes share sequence sim ilarities. In our approach, this difficulty can be circumvented by carefully designing PCR primers.

Our semiquantitative RT-PCR approach is considerably straightforward. Nonetheless, as any empirical end-point PCR-based quantification, it requires correction for experimental variations

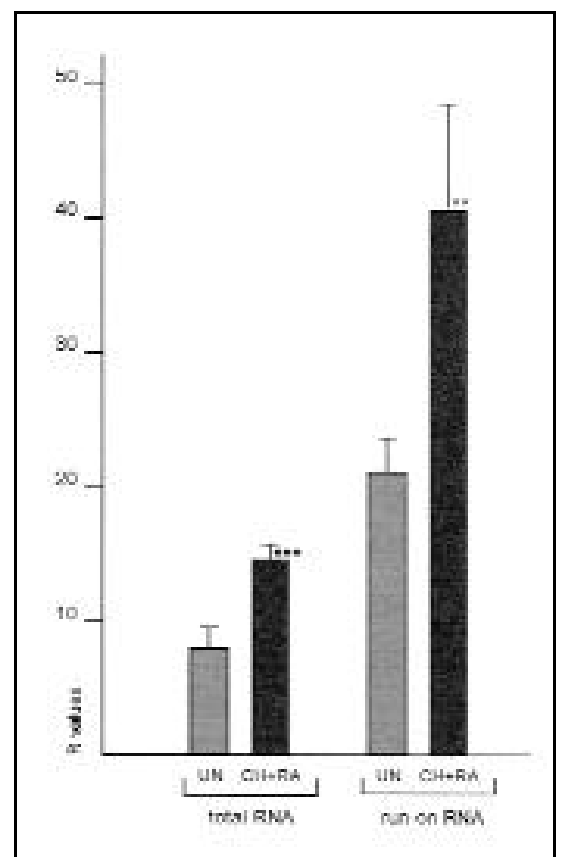

Figure 2. An application of the proposed protocols. SK-N-BE cells were treated with RA and cycloheximide for $4 \mathrm{~h}(1,8)$, and the RET gene expression and transcription levels were determined using the G3PDHgene as an internal control. The histogram depicts $\mathrm{R}$ values from total and nuclear run-on RNA in treated $(\mathrm{RA}+\mathrm{CH})$ and untreated (UN) cells. Mean values and error bars refer to six independent $\mathrm{R}$ calculations. Asterisks indicate significance of results; three asterisks indicate $P<$ 0.01 , while two asterisks indicate $P<0.05$. in individual RT and PCR efficiencies (4), which may be very time consum ing. As an alternative, new procedures using real-time online quantification [LightCycler ${ }^{\circledR}$ or TaqMan ${ }^{\circledR}$ (6)] could be combined to the proposed run-on protocol, thus acquiring improved standards of quantification.

\section{REFERENCES}

1.Bunone, G., M.G. Borrello, R. Picetti, I. Bongarzone, F.A. Peverali, V. De Franciscis, G. Della Valle and M.A. Pierotti. 1995. Induction of RET proto-oncogene expression in neuroblastoma cells precedes neuronal differentiation and is not mediated by protein synthesis. Exp. Cell Res. 217:92-99.

2.Ceccherini, I., R. Bocciardi, L. Yin, B. Pasini, R.M.V. Hofstra, M. Takahashi and G. Romeo. 1993. Exon structure and flanking intronic sequences of the human RET protooncogene. Biochem. Biophys. Res. Commun. 196:1288-1295.

3.Edery, P., C. Eng, A. Munnich and S. Lyonnet. 1997. RET in human development and oncogenesis. Bioessays 19:389-395.

4.Freeman, W.M., S.J. Walker and K.E. Vrana. 1999. Quantitative RT-PCR: pitfalls and potentials. BioTechniques 26:112-125.

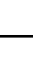

5.Groudine, M., M. Peretz and H. Weintraub. 1981. Transcriptional regulation of hemoglobin switching in chicken embryos. Mol. Cell. Biol. 1:281-288.

6.Heider, C.A., J. Stevens, J.K. Livak and P.M. Williams. 1996. Real time quantitative PCR. Genome Res. 6:986-994.

7.Merscher, S., R. Hanselmann, C. Welter and S. Dooley. 1994. Nuclear runoff transcription analysis using chemiluminescent detection. BioTechniques 16:1024-1026.

8.Patrone, G., A. Puliti, R. Bocciardi, R. Ravazzolo and G. Romeo. 1997. Sequence and characterization of the RET proto-oncogene $5^{\prime}$ flanking region: analysis of retinoic acid responsiveness at the transcriptional level. FEBS Lett. 419:76-82.

9.Rolfe, F.G. and W.A. Sewell. 1997. Analysis of human interleukin- 5 gene transcription by a novel nuclear run-on method based on the polymerase chain reaction. J. Immunol. Methods 202:143-151.

10.Sandaltzopoulos, R., T. Blank and P.B. Becker. 1994. Transcriptional repression by nucleosomes but not $\mathrm{H} 1$ in reconstituted preblastoderm Drosophila chromatin. EMBO J. 13:373-379.

11.Schubeler, D. and J. Bode. 1997. A sensitive transcription assay based on simplified nuclear run-on protocol. Elsevier Trends J. Technical Tips Online. Tip T01176.

12.Schubeler, D., C. Mielke, K. Maass and J. Bode. 1996. Scaffold/matrix-attached regions act upon transcription in a context-dependent manner. Biochemistry 35:11160-11169.

13. Tahira, T., Y. Ishisaka, F. Itoh, M. Nakatasu, T. Sugimura and M. Nagao. 1991. Expression of the RET proto-oncogene in human neuroblastoma cell lines and its increase during neuronal differentiation induced by retinoic acid. Oncogene 6:2333-2338.

G.P. is supported by a Fellowship awarded by the Fondazione Italiana per la Ricerca sul Cancro (FIRC), and F.P. is supported by Italian Telethon. The financial support of Italian Telethon (grant no. E791) and of the Associazione Italiana per la Ricerca sul Cancro (AIRC) are gratefully acknowledged. Address correspondence to Dr. Giovanna Patrone, Laboratorio di Genetica Molecolare, Istituto G. Gaslini, Università di Genova, Largo G. Gaslini 5, 16148, Genova, Italy.e-mail: aldamar@tin.it

Received 29 November 1999; accepted 11 July 2000.
G. Patrone, F. Puppo,
R. Cusano, M. Scaranari, I. Ceccherini, A. Puliti ${ }^{1}$ and R. Ravazzolo Università di Genova, Genova ${ }^{1}$ Università di Pisa Pisa, Italy 